Journal of Social Sciences 6 (2): 153-161, 2010

ISSN 1549-3652

(C) 2010 Science Publications

\title{
Authentic Assessment and Pedagogical Strategies in Higher Education
}

\author{
Chan Yuen Fook and Gurnam Kaur Sidhu \\ Faculty of Education, University Technology MARA, \\ Campus Section 17, 40200 Shah Alam, Selangor, Malaysia
}

\begin{abstract}
Problem statement: Researchers have noted that there is a mismatch between curriculum content and assessment practices in higher education. At the moment, the focus is still on the assessment of learning and not much on assessment for learning. Therefore, this study was conducted to examine the implementation of authentic assessment in higher education in Malaysia. Approach: The study employed a qualitative research method and involved the use of instruments such as interviews, document analysis and unobtrusive classroom observations to collect the relevant data in the classrooms of a three-credit hour course from a Masters degree programme. The total population consisted of 2 lecturers and 20 students from the two selected intact TSL 752 classes. Results: In this study, researchers identified different types of authentic assessment with the suitability to certain pedagogical strategies, their effects on students' learning and the appropriate procedures of conducting authentic assessments. The findings indicated that alternative and authentic assessment have more acceptance from students and should therefore be viewed as an alternative to traditional standardized assessment. Conclusion/Recommendations: The study identified that assessment strategies should be closely related to teaching and learning. Assessing authentic performances should become integral parts of the instructional cycle and feedback provided by the lecturer and peers should be formative in order to help the students assess their strengths and weaknesses, identifying areas of needed growth and mobilizing current capacity.
\end{abstract}

Key words: Assessment, teaching and learning, higher learning institutes

\section{INTRODUCTION}

Assessment is central to teaching and learning. The assessment information is needed to make informed decisions regarding students' learning abilities, their placement in appropriate levels and their achievement. According to Sadler (2005), assessment refers to the making of evaluation on students' overall performance and generating assumptions regarding their learning and production education-wise, which include the quality or achievement in tasks such as tests, projects, reports and examinations. In the other hand, the success of any assessment is depending on the effective selection and use of appropriate procedures as well as on the proper interpretation of students' performance. Thus, assessment procedures also help in evaluating the suitability and effectiveness of the curriculum, the teaching methodology and the instructional materials.

Van der Watering et al. (2008) note that students considered the traditional assessment to be primarily a measurement consisting of comprehension and application-based questions that required the drawing of conclusions, problem solving, analysis, interpretation and critical thinking. The correlations between student preferences and assessment perceptions in their findings were not significant due to the existence of a distinction between student preferences and their perceptions. Today, a common method advocated to improve student achievement is the use of formative assessments, both to improve the pedagogical practises of teachers and to provide specific instructional support for lower performing students (Dunn and Mulvenon, 2009). In fact, the formative assessment methods of assessing students take into account variation in students' needs, interests and learning styles; and they attempt to integrate assessment and learning activities. In the integral process of learning and instruction only high quality assessment can facilitate high-quality learning. Mueller (2005) observes that while researchers in higher education have proposed a series of changes such as alternative assessment to replace traditional assessment, these proposals have yet to be implemented in many institutions.

Corresponding Author: Chan Yuen Fook, Faculty of Education, University Technology MARA, 40200 Shah Alam, Malaysia Tel: 603: 55227401 Fax: 603: 55227412 


\section{J. Social Sci., 6 (2): 153-161, 2010}

Therefore, institutions of higher education have to revisit their purpose of assessment if they hope to equip their learners with skills and competencies needed to succeed in today's workplace. Boud (2000) highlights that such an endeavor calls not only for formative but what he terms as 'sustainable assessment'. He cautions that current assessment in higher education is inadequate to the task of preparing students for a lifetime of learning. Besides that, Boud and Falchikov (2005) suggest that educators need to move from summative assessment that focuses on specifics, standards and immediate outcomes to more sustainable assessment that can aid students to become more active learners not only in managing their own learning but also assessing themselves to life beyond the end of the course. They added that there has been considerable critique of both the adequacy of current formative assessment to aid student learning to the ill effects of summative assessment. Boud and Falchikov (2005) further highlight that most of the critique has focused on the effect on learning within courses not on learning following graduation. They note that balancing this, however has been the flourishing of an array of authentic assessment procedures designed to overcome the limitations of traditional unseen summative and norm referenced standardized tests.

Authentic assessment emphasizes the practical application of tasks in real-world settings. Mueller (2005) defines authentic assessments as direct measures of students' acquired knowledge and skills through formal education to perform authentic tasks. The realistic contexts can make problems more engaging for students and help the teachers evaluate whether a student who can solve a problem in one context can transfer the skills to a similar setting. Besides that, research has conclusively demonstrated that the use of formative assessment facilitates improvement in instructional practices, identifies "gaps" in the curriculum and contributes to increased student performance (Dunn and Mulvenon, 2009). Hence, to perform these authentic tasks, students need to construct their own meaning to the world through the application of previously acquired information from classroom teaching and learning (Airasian, 2005; Linn and Miller, 2005).

Pellegrino et al. (2001) assert that authentic assessments provide multiple paths to demonstration of learning in comparison to traditional assessments like answering multiple-choice questions that lack variability, owing to students' ability to demonstrate knowledge and skills they possess. Authentic tasks tend to provide more freedom to demonstrate their competencies, for example, business proposals, projects, portfolios, artwork and videos, among other tangible products. Additionally, options for authentic assessment may include evaluating the work of cooperative learning groups, ideas for assessing problem-based or active learning experiences. These methods of assessment practices may help to create options for divergent learners and provide opportunities for applying practical and higher order cognitive skills. Through these, students are encouraged to take an active role in their own learning from the elaborate projects of the authentic assessments. The nature of these assessments contribute to constructive and transformative learning. Importantly, formative types of authentic assessments help to decrease the level of anxiety generated by emphasizing the aspect of the 'doing'.

Craddock and Mathias (2009) reiterate that formative assessments produced a much more favorable outcomes when the collected data is compared with results obtained from summative assessments due to most of the participants were encouraged to open up because they felt that there were not intimidated with formative assessments. They however cited Hamdorf and Hall (2001), in pointing out that a poorly developed formative assessment can potentially be unproductive and dangerous to students who are weak when referred to the relations between learning and assessment and how formal assessment can undermine the curriculum's learning target. Dunn and Mulvenon (2009) go on further to add that it is difficult to conclude that the use of formative assessments does not provide information to help improve instructional practices or student outcomes in classrooms. Nevertheless, the many benefits of authentic assessments display the fact that certain procedures and practices in higher education need to be initiated to move this agenda in the right direction.

In the past assessment was rarely seen as a process of bringing out the potential that exists within students and creating an opportunity for them to demonstrate what they were able to do. Most of the time, assessments were only used to certify students' learning. Many learning institutes have forgotten the ultimate purpose of the assessment actually is not only to prove but also to improve students' learning (Boud and Falchikov, 2005; Linn and Miller, 2005; Craddock and Mathias, 2009). On top of that, assessment was rarely interpreted in such broad concepts as today-i.e., as an 'an integral part of the educational curriculum and fulfilling multiple purposes: Fostering learning, improving teaching, providing valid information about what has been done or achieved and enabling pupils and others to make sensible and rational choices about 
courses, careers and other activities. Thus, researchers have noted that there is a mismatch between curriculum content and assessment practices. At the moment, the focus is still on the assessment of learning and not much on assessment for learning (Boud and Falchikov, 2005). If the current move is to witness any success in teaching and learning, it is only sensible that lecturers in institutions of higher education are implementing authentic assessment. Therefore one has to examine the implementation of authentic assessment in higher education. The dean, coordinators and lecturers needs to be consulted regarding with policy of authentic assessment in the faculty. Furthermore, students as the main clients in higher education need to be consulted as to their views and perceptions of authentic assessments and to what extent classroom assessments will help prepare them to the needs of internationalization and globalization. Hence, the study was specially designed to examine the implementation of authentic assessment in higher education. Specifically, the objectives of the study were to identify:

- The different types of authentic assessment in higher education

- The pedagogical strategies that suit authentic assessments in higher education

- The effects of authentic assessment on students' learning in higher education

- The appropriate procedures of conducting authentic assessments in higher education

This study endeavored to answer the following research questions:

- What are different types of authentic assessment that practiced in higher education?

- What pedagogical strategies that suit authentic assessments in higher education?

- What are the effects of authentic assessment on students' learning in higher education?

- What are the appropriate procedures of conducting authentic assessment in higher education?

\section{MATERIALS AND METHODS}

This study investigated the implementation of authentic assessment in an institution of higher education in Malaysia. The chosen institution was a Faculty of Education located in a public university in the state of Selangor, Malaysia. This study employed a qualitative research method to investigate different kinds of assessment, pedagogical strategies that suit authentic assessment, effect of authentic assessment and appropriate procedures of the implementation of authentic assessment in the higher learning institute. In this qualitative study, the researchers were the research instruments for data collection in their own classrooms (Ary et al., 2002). Qualitative inquiry shows concern for context-it assumes that human behavior is contextbound and therefore is inseparable from social, historical, political and cultural influences. The concept of human-as-instrument emphasized the unique role that qualitative researchers play in their inquiry. Because this study focuses on lecturers' and students' experiences, researchers also required an instrument flexible enough to capture the complexity of the human experience. Thus, researchers in this study talked with people in the setting, observed their activities, read their documents and written records and recorded the relevant information in field notes and journal.

The main aim of the study was to investigate the pedagogical strategies, effect of authentic assessment on students' learning and appropriate procedures of conducting authentic assessment in a course in higher education. The course chosen was TSL 752 Trends in Testing, Assessment and Evaluation-a $42 \mathrm{~h}$ course from a Masters degree programme. This course focused on testing, assessment and evaluation which is deemed useful for world-be teachers and practitioners. Course participants undertaking this course have the opportunity to construct, administer, interpret, analyze and evaluate tests and assessments. Besides that, course participants are also encouraged to take part in active discussions on current trends and issues in testing, assessment and evaluation. Furthermore, it must be stressed that this is a compulsory core subject for all students undertaking a Masters Degree in Education at the Faculty of Education in this study. The instruments employed in this study included interviews, classroom observation checklists and document analysis templates. Semi structured interviews were conducted to investigate lecturers' practices in authentic assessment. A structured interview guide was also employed to gain insights into students' perceptions of authentic assessment in the classroom. Triangulation of findings was further enhanced through classroom observations and document analysis.

The target population of this study were lecturers and students at the Faculty of Education of a public university in Selangor, Malaysia. The study was confined to two full-time lecturers (Lecturer A and Lecturer B) teaching the identified course in this study (TSL 752) and students taught by the two lecturers. Cluster sampling was employed because it was viewed more feasible to select groups of individuals rather than 
individuals from a defined population (Cohen et al., 2005). Once the two lecturers had been chosen the multistage cluster sampling method was applied (Cohen et al., 2005). Each cluster involved the lecturer and one (1) intact TSL 752 class of students that each lecturer was teaching. In this study, Lecturer A's class is referred to as Class A while Lecturer B's class is referred to as Class B. From each TSL 752 class 10 students were randomly selected for the study-identified as Students A1-A10 for Class A and Students B1-B10 for Class B. Hence the total population consisted of 2 lecturers and 20 students from the two selected intact TSL 752 classes. A total of 2 classroom observations of Seminar Paper Presentation sessions were carried out in each identified TSL 752 classrooms. Document analysis involved analysis of 6 different students' assignments from these two intact classes was also conducted. The assignments analysis included a total of 6 samples of portfolio, 6 samples of test construction and evaluation projects ( 3 from each class) and 6 samples of case study assignments (3 from each class) from the students.

\section{RESULTS}

Given below is the result and discussion of the main findings obtained from the study.

Types of authentic assessment: Document analysis conducted by the researchers indicated that the course chosen in this study is practicing authentic assessment. The intention of assessing the verbal knowledge and procedural knowledge can be seen from the following instructional objectives stated in this course:

- Apply the principles of classroom assessment

- Construct and administer various types of classroom assessment

- Interpret and analyze test scores

- Conduct item analysis and forming item bank

- Describe other forms of classroom assessment

- Identify latest trend development on current issues in testing and evaluation

Besides that the assessment methods employed in this course included a variety of assessment techniques such as portfolio assessment, seminar paper review, a case study, a collaborative project work and a test. Given below is the weighing for each of the assessment component of the course:

Portfolio

$10 \%$

Article/seminar paper review

$10 \%$

Case study (assessment practices)
Project (test construction and evaluation)

$40 \%$ Test

$20 \%$

The assignments and allocation of marks indicated the emphasis of authentic assessment employed in this course. The allocation of $40 \%$ of marks for the project indicated the importance of assessing the competencies of a teacher in the natural settings. Besides that, there are a variety of assessment methods employed in this course with an emphasis on the performance tasks and on-going formative assessment. Basically, students in course felt that their assessment tasks were 'real' and to a great extent mirrored the knowledge, skills and competencies they would need in their future workplace. These performance-based assessments can provide information on how a student performs on each of the specific criteria that make up a more general performance or product. Selected students interviewed agreed that lecturers can use these performance-based assessments for many purposes: Grading students, constructing portfolios of student work, diagnosing student learning and helping students recognize the important steps in a performance or product. They even emphasized that whatever the purpose of authentic assessment, it should be specified at the beginning of the assessment process so that proper performance criteria and scoring procedures can be established.

Pedagogical strategies that suit authentic assessments: Open-ended interviews were conducted with the two lecturers to identify pedagogical strategies that suit authentic assessment. Both Lecturer A and Lecturer B expressed a need for more intellectual stimulation in their profession. For example, Lecturer A said:

It will be good if from time to time we can attend courses in instruction and assessment. There are so many things that we need to know in order to made our teaching more interesting. Transformative learning and authentic assessment are two new concepts for most of the lecturers in the faculty. We need to know how to do it

Similarly, Lecturer B felt that the lecturers at the faculty needed more support in the area of professional learning. Both of them have some exposure to transformative learning. They know that transformative learning is the kind of learning where students try to find meaning in their lives and the learning will lead to deep and persistent shifts in the learner's perspective and understanding. However, they admitted that they 
still do not have enough knowledge to implement transformative learning that involves self-examination, critical assessment of assumptions, recognizing, exploring options, formulating a plan of action and reintegration of transformative learning in the classroom. However, both of them agreed that the method of delivery in university has to be studentcentered where the educator's main role is more than of a facilitator guiding students through mind probing questions and tasks in testing their critical thinking, decision making as well as problem solving skills. This involves students playing a more active role than the instructor. When Lecturer A was asked to describe his teaching in his class, he said:

We know that we should apply studentcentered methods. However, we always find that our students are always too passive even though they are all adult learners. They prefer to listen to the lecturers than sharing their ideas. They try their best to comply to lecturer's expectation. I think this is the culture of learning in the Asian countries

Lecturer B added:

Usually, my students are quiet and passive. They don't like to take part in the discussion even though they are master students. They don't like to volunteer themselves for presentation or talking in front. However, if you assign works to them, they will do it. They like to have clear guidelines from the lecturer

The above comments reflect that lecturers need to plan some activities to engage students in their classroom. What students often value in assessments are authentic assignments that articulate clear expectations of their competencies and how assignments grades are determined. These would call transparency in aspects such as what will be assessed, how it will be assessed and when it will be assessed. Both lecturers also stressed that authentic assessment needed to be contextualized and relevant to the real world and should be formative in nature. Lecturer $\mathrm{A}$ was happy with the authentic assessment implemented in TSL 752 such as the case study, project, seminar paper presentation and portfolio. However, Lecturer B was rather hesitant about the authenticity of these assessment procedures. He pointed out that some students were copying assignments from their seniors. Many students never consulted him regarding with their assignments. There were also a few students who were reluctant to do their parts in the group project. Thus, Lecturer B was questioning on the authenticity of the assessment methods. Both of the lecturers agreed that authentic assessment is new, but they do believe that authentic assessments can solve many learning problems in the classroom. In order to implement authentic assessment effectively in the faculty, both of the lecturers proposed every authentic assessment should:

- Have a clear purpose that identifies the decision to be made from the performance assessment

- Identify observable aspects of the student's performance or product that can be judged

- Provide an appropriate setting for judging the Performance or product

- Provide a judgment or score to describe performance

Effect of authentic assessment on students' learning: Many students had wrong concept of the portfolio at the beginning of the course. Most of them perceived portfolio as a purposeful collection of pieces of student work rather than a learning tool. When they were asked to document their learning experience in this course and share their opinions of doing their assignments with the lecturer and their coursemates, they found that it was very difficult for them to follow. Many students highlighted that they did not know what to do with the portfolio. Writing down their experiences and opinions were not a common practice. Furthermore, sharing their experiences and thinking were not their habits as well. However, students have changed their perception at the end of the course. Students reported that the portfolios enabled them to review what they had learned:

As I said, I have learned a lot during the course (Student A1). Of course, it is time consuming to write what you have experienced in the course; however, it is a valuable self reflection process that can help us to improve our learning (Student B3). We need to review our learning from time to time so that we can really understand what we are doing (Student B7). Actually, portfolio is a communication tool between lecturer and students. Comments and advises written by the lecturer can really help me to identify and solve my learning problems (Student A6). I do share my portfolio with my course mate. Undeniably, we learned a lot from reading other students' portfolios (Student A4) 
A few students highlighted that they had some negative perceptions towards portfolio assessments. Some felt that it was a sheer waste of time whilst others stressed they did not know what to write as they were most of the time repeating the same thing. Nevertheless a majority of them agreed that the implementation of the portfolio assessment was necessary. This was because they realized the portfolio could help them to assess their own contribution and to emphasize the learning process in the project. During the interviews with the selected students it was revealed that what the students gained from the test construction and evaluation project was tremendous. Most of the students noticed that the emphasis of the project is on doing, not merely knowing. Many students wrote about their learning process, how they constructed their test paper and finally successfully analyzed the test scores and conducted item analysis. Many students in the course have positive things to say about the project:

Now I know how to construct a test in a proper way (Student A9). I am able to construct a Table of Specification (Student B4). In school, we never use the Table of Specification. However, I think I will use it in the future (Student B10). If you ask me how to construct a test, I can provide you with better advices now (Student A7). I am even able to interpret the test score in a professional manner (Student B3). Furthermore, we could do item analysis easily with the template created by our lecturer by using Microsoft Excel that we always think it is too difficult to be implemented in school (Student A8)

Another comment expressed during the interview (Student B1):

I think the project is really an authentic assessment. It emphasizes the practical application of the tasks in real-world settings. It provides a basis for teacher to evaluate both effectiveness of the process and the product resulting from the performance of constructing and evaluating a test

Another opinion on a project (Student A8):

However, it is really time consuming. I think may be we should also do the project in the class. We are having so much problems to meet with our group members. We are all working adults. We meet in the course all together only seven times in a semester. Thus, it is not easy for us to sit down to discuss and to do our projects together. It is really a heavy burden to us

\section{According to Lecturer B:}

Our students are still maintaining active participation in their projects. They are learning from the process. They are doing well and all of their own without very much of lecturer leadership. It shows initiative on the part of the students. So, this is the team work that we need to maintain

Thus, if lecturers want to create new forms of assessment in the classroom, it is necessary to generate new situations in which students are more likely to give positive reactions to these situations. The concept of dynamic assessment as an active process in which students and lecturers participate provides a model for new assessment techniques, which are aligned with new vision for teaching and learning. Other than project and portfolio assessments, there were two other assessment strategies namely seminar paper presentation and case study were employed in this course. Students in course felt that seminar paper presentation provided a good opportunity for students to train themselves to become a good paper presenter in seminars or conferences. A student made comments on this:

Frankly, 1 think seminar paper presentations have their own value. Students are able to share their reading and knowledge in testing and assessment. We really have fun. We laugh at our friends, but we do learn a lot from each other during the presentation

Even though there was an overall satisfaction on seminar paper presentation, a few students commented on the dissatisfying facilities in the faculty. They were upset with the frequent dysfunction of the laptop and liquid crystal display equipments at the faculty. They lamented that:

When we were having our presentation, the computer was not functioning. Finally we have to present our papers without the PowerPoint Presentation. I just hope our lecturer will not minus our marks. Sometimes, the air condition was not functioning too. We were trapped in a warm and stuffy room. All these unexpected conditions were affecting our performance 


\section{J. Social Sci., 6 (2): 153-161, 2010}

When asked about the effect of case study on their learning, a few of the students have this to say:

The problem is to identify the case to study in the school. We are in the school system; therefore it is not easy for us to identify the testing or assessment problems. We need to have a more sensitive and critical perception towards the assessment systems in our schools. Therefore, we need to learn more about classroom assessment. However, we learn a lot from the case study. We were trained to evaluate the system. We become a more observance person

Students in course shared the same opinions that both case study and seminar paper presentation were similar to project and portfolio assessments. All these assessment procedures ask students to perform, create, produce or do something that requires them to use higher-level critical thinking and problem solving skills; the assessment tasks themselves represent meaningful instructional activities; the tasks themselves are also relevant to real-life tasks or represent those that are common to a particular discipline.

Appropriate procedures of conducting authentic assessment: Both lecturers stressed the importance of good planning to provide valid, reliable and useful information concerning student achievement. A clear guideline is needed to guide students to do their assignments. Information such as types of assignments, individual, pair work or group work, allocation of marks and guidelines of conducting their assignments should be provided to students. Lecturer A stated that good planning calls for the "formulation of explicit expected learning outcomes' so that suitable tasks can be constructed to measure the intended knowledge, skills and understanding while minimizing the influence of irrelevant or ancillary skills. She pointed that all learning tasks under the TSL 752 course were well planned out with explicit learning outcomes.

Both Lecturers A and B pointed out in planning all the assessments such as the preparation of student assignments like portfolio, project, seminar paper presentation and case study were planned with explicit learning outcomes and guidelines. Both learning outcomes and guidelines were well communicated to students orally and in written form through printed handouts. Similarly, the main criteria for grading and scoring were also communicated to the students. At this juncture, both lecturers highlighted that authentic tasks required careful planning and monitoring to avoid plagiarism-an issue of grave concern among lecturers in their faculty and institutions of higher education.

One distinct feature of authentic assessment is providing prompt feedback so that the focus is not on assessment of learning but more importantly, assessment for learning. Both lecturers pointed out that in their course there were a number of authentic assessment that were carried out by students working collaboratively either in pairs or small groups of four to five students. In these assessments students were encouraged to make appointments with the lecturer concerned to discuss and review their work in progress. Lecturer A indicated that approximately $25 \%$ of his students from Class A came for the consultation and feedback on their work in progress. On the other hand, Lecturer B indicated that less than $20 \%$ of his students came to see him even though he had 'an open door' policy. Interview data also indicated students only come to consult with the Test Construction and Evaluation Project and the Case Study. None of the students from the two classes come to check for the implementation of Portfolio and Seminar Paper Presentation. Lecturer A pointed out the reason this phenomenon may due to the nature of the assignments. Both Test Construction and Evaluation Project and Case Study are extended response performance tasks, however, both Seminar Paper Presentation and Portfolio are restricted response performance tasks. For the extended response performance tasks, students normally need more guidance from the lecturer. However, both extended and restricted authentic assessments should be an ongoing formative process where students and lecturers can work collaboratively seeking to make meaning of the teaching and learning process.

Both lecturers and students must see assessment as an integral part of the instructional process and a critical component of a coherent educational experience. First and foremost, findings in this study highlight that for effective learning to become an agenda in higher education, assessment tasks must be derived from and simulate authentic situations. Students express a high preference for tasks that they perceive to be 'real'. Therefore HE faculties /departments/schools are challenged to spearhead polices to ensure assessments given do not push students into rote reproduction but encourage student self-assessments that promote reflection, construction of meaning and self-monitoring of learning. Henceforth, the challenge lies in equipping students with the relevant tools for managing and monitoring their own learning in order to become autonomous life-long learners that can remain competitive in the era of globalization. 
Hence, assessment assignments must not only indicate the alignment between expected learning outcomes to make sense of the 'curriculum loop' but more importantly take into consideration assessments that require them to synthesize knowledge and skills learnt in the classroom and apply it for 'real' situations in their future workplace. Such a move would certainly enable students to be more marketable and in the long run push forward the $\mathrm{HE}$ agenda of international recognition.

\section{DISCUSSION}

This study highlighted that assessment practices in this particular course indicated favorable emphasis being given to formative assessment because $80 \%$ of the total marks have been allocated to on-going assessments and only $20 \%$ of the marks is for the test. Moreover, students interviewed also agreed that project, case study and portfolio assignments given were to a great extent real and authentic assignments/task that they could relate to their future workplace. Hence these students felt that the current emphasis on formative assessment was a step forward in the right direction.

Nevertheless it is point to note that the study did not look into the relationship between the student preferences and their test scores. According to Van de Watering et al. (2008) study, there are clear differences between assessment type preferences and the resulting scores on the assessment formats, which are based on the students' preferences. Students with matching perception of the cognitive processes' level will have better results if compared to students with misperception of the cognitive processes in regards to the results produced in answering the question of the relations between the students' perceptions and assessment due to implications that students should have the opportunity to show their competence on different assessment methods in order to build a clear assessment preferences (Van de Watering et al., 2008). Consequently it would perhaps be pertinent that a future study look into the relationship between assessment preferences and students' test score performance.

The study also identified that though students displayed a favourable attitude towards transformative learning with a focus on student-centred approach, lecturers on the other hand were still not quite on par with the implementation procedures. According to Birenbaum and Feldman (1998), students will be motivated to perform at their best if they are provided with assessment format they prefer. In this case, Sadler (2005) further stated that the students' level regarding their past performances is the indicator for evaluation that is called 'self-referenced assessment and grading', with the amount of improvement the students produce. This type of assessment seemed to seep into the overall assessment methods even though it is not considered as a proper way of assessing or grading students' performance in most of the institutions.

Another interesting point highlighted by the findings in this study was the fact that even though students revealed a positive attitude towards formative assessment they were not very much into learning from their assessments. They did not take the opportunity provided by lecturers to make appointments for consultation. In the formative assessment equation, students must be encouraged to talk about their work and feedback obtained so that they can be truly engaged in the learning process. Lombardi (2008) highlights that students today demand for greater transparency but there exist a number of barriers that need to be addressed. Among them include changing student attitudes and faculty resistance towards formative assessment for authentic learning.

Nevertheless this study has also revealed the many benefits that can be reaped from authentic assessment. For example, the portfolio helps students to reflect on their own learning, the project helps students to learn from doing and to think critically, and the presentation makes the students to be more confident and communicative in front of the audiences. However, in order to make authentic assessment a successful endeavour in higher education, the faculty needs to ensure effective planning mechanisms and clear expectation and procedures are in place. Sadler (2005) concluded in his paper that the present assessment culture can be seen in many ways and features according to similar expectations criteria-based assessment and grading, variations of individual's understanding and how it is applied; and limitations of comprehensive data and information. Sadler (2005) finding is a good reference for improvement of assessment practices in learning institutions.

\section{CONCLUSION}

The findings indicated that alternative and authentic assessment have more acceptance from students and should therefore be viewed as an alternative to traditional standardized assessment. The assessment methods employed in the course were a new experience to all students in this course. The assignments gave the lecturers and students an insight into their group members' thought processes and the evidence gathered during the process. Many students enjoyed the experience despite acknowledging the fact 
that it was rather time consuming as most of them are working adults with family and job-related commitments. This study also revealed that the assessment criteria and practice need to be explored further to improve the validity and reliability and therefore fairness of assessment practices. Furthermore the assessment of students' progress and achievement should be carried out in a manner that does not cause anxiety in the students. The summative form of testing that permeated the traditional curricula would not be fair to students. Hence, the traditional paper-and pencil tests no longer cover the variety of activities and tasks that take place in the classroom. The findings have witnessed a major shift from strictly summative testing tools and procedures to a more humanistic, authentic and informal techniques that stress formative assessment.

\section{REFERENCES}

Airasian, P.W., 2005. Classroom Assessment: Concepts and Applications. 5th Edn., McGraw-Hill, Boston, ISBN: 0-07-248869-7, pp: 234.

Ary, D., L.C. Jacobs and A. Razavieh, 2002. Introduction to Research in Education. 6th Edn., Wadsworth, Canada, ISBN: 0-534-24665-6, pp: 424.

Boud, D. and N. Falchikov, 2005. Redesigning assessment for learning beyond higher education. Res. Dev. Higher Educ., 28: 34-41.

Boud, D., 2000. Sustainable assessment: Rethinking assessment for the learning society. Stud. Continu. Educ., 22: 151-167.

Birenbaum, M. and R.A. Felman, 1998. Relationships between learning patterns and attitudes towards two assessment formats. Educ. Res., 40: 90-97.

Cohen, L., L. Manion and K. Morrison, 2005. Research Methods in Education. 5th Edn., Routledge/Falmer, New York, ISBN: 0-41519541-1, pp: 101.

Craddock, D. and H. Mathias, 2009. Assessment options in higher education. Assess. Evaluat. Higher Educ., 34: 127-140. DOI: $10.1080 / 02602930801956026$
Dunn, K.E. and S.W. Mulvenon, 2009. A critical review of research on formative assessments: The limited scientific evidence of the impact of formative assessments in education. Pract. Assess. Res. $\quad$ Evaluat., $14: \quad 1-11$. http://pareonline.net/getvn.asp?v=14\&n=7

Hamdorf, J.M., and J.C. Hall, 2001. Surgical education. Aust. N. Z. J. Surg., 71: 178-83.

Linn, R.L. and M.D. Miller, 2005. Measurement and Assessment in Teaching. 9th Edn., Pearson, New Jersey, ISBN: 0-13-127393-0, pp: 250-256.

Lombardi, M. M., 2008. Making the grade: the role of assessment in authentic learning. ELI Paper 1. http://net.educause.edu/ir/library/pdf/ELI3019.pdf

Mueller, J., 2005. The authentic assessment toolbox: Enhancing student learning through online faculty development. J. Online Learn. Teach., 1: 1-7. http://jolt.merlot.org/documents/vol1_no1_mueller _001.pdf

Pellegrino, J.W., N. Chudowsky and R. Glaser, 2001. Knowing What Students Know: The Science and Design of Educational Assessment. National Academies Press, Washington, DC., USA., ISBN: 10: 0309072727, pp: 382.

Sadler, R., 2005. Interpretations of criteria-based assessment and grading in higher education. Assess. Evaluat. Higher Educ., 30: 175-194. DOI: 10.11080/0260293042000264262

Van der Watering, G., D. Gijbes, F. Dochy and J. van der Rijt, 2008. Students' assessment preferences, perceptions of assessment and their relationships to study result. High Educ., 56: 645-658. DOI: 10.1007/s10734-008-9116-6 